\title{
ANÁLISIS Y PROPUESTA PARA LA INCLUSIÓN DEL ARTE EN EL PLAN EDUCATIVO DE COLEGIO EMBLEMÁTICO DE LIMA, PERÚ PARA FOMENTAR LA INTERCULTURALIDAD.
}

\author{
ANALYSIS AND PROPOSAL FOR THE INCLUSION OF ART IN THE \\ EDUCATIONAL PLAN OF AN EMBLEMATIC SCHOOL OF LIMA, PERU TO \\ PROMOTE INTERCULTURALITY.
}

\author{
Manuel José Kamichi Miyashiro ${ }^{1}$ \\ Magister en Política Social \\ Universidad Nacional Mayor de San Marcos \\ Manuel.Kamichi@unmsm.edu.pe \\ Pamela Raquel Ascoy García ${ }^{2}$ \\ Magister en Política Social \\ Universidad Nacional Mayor de San Marcos \\ pamela.ascoy@unmsm.edu.pe \\ Kelly Diana Chinguel Cajo ${ }^{3}$ \\ Magister en Política Social \\ Universidad Nacional Pedro Ruiz Gallo \\ kdianachc@gmail.com
}

Resumen: El presente trabajo se divide en dos partes, primero se realiza un análisis situacional sobre la educación intercultural en el colegio emblemático seleccionado para la investigación; y después, se diseña una propuesta de proyecto que tiene como eje principal el arte como herramienta pedagógica para la interculturalidad. Entre los principales resultados se encuentra que en el colegio no hay ninguna enseñanza relacionada a la educación intercultural y los estudiantes desconocen sobre esta, pero sí existe prácticas artísticas en los sitios donde viven la mayoría de ellos que puede ser usada por el colegio para fomentar la interculturalidad a través del arte.

Palabras claves: educación intercultural, arte, interculturalidad, colegio emblemático, proyecto social.

Abstract: This paper is divided into two parts. First, a situational analysis of intercultural education in the emblematic school selected for the research is carried out; and then, a project proposal is designed, which has as its main axis art as a pedagogical tool for

\footnotetext{
${ }^{1}$ Bachiller en Comunicaciones, investigador académico.

${ }^{2}$ Licenciada en Trabajo Social, trabajadora social del Hospital Santa María de Cutervo

${ }^{3}$ Licenciada en Sociología, especialista en bienestar de beneficiarios del PRONABEC (Programa Nacional de Becas y Crédito Educativo)
} 
interculturality. Among the main results it is found that in the school there is no teaching related to intercultural education and the students do not know about it, but there are artistic practices in the places where most of them live that can be used by the school to promote interculturality through art.

Key words: intercultural education, art, interculturality, emblematic school, social project.

Resumo: 0 presente trabalho é dividido em duas partes, primeiro é realizada uma análise situacional sobre a educação intercultural na escola emblemática selecionada para pesquisa; e, em seguida, é projetada uma proposta de projeto que tem como eixo principal a arte como ferramenta pedagógica de interculturalidade. Entre os principais resultados está que na escola não há ensino relacionado à educação intercultural e os alunos não sabem sobre isso, mas há práticas artísticas nos locais onde a maioria deles vive que podem ser utilizados pela escola para promover a interculturalidade através da arte.

Palavras chaves: educação intercultural, arte, interculturalidade, escola emblemática, projeto social.

\section{INTRODUCCIÓN}

Las prácticas artísticas revelan la relación que hay entre la cultura producida por un sujeto que es parte de una comunidad y es transformada por ella a la vez (Schwerter, 2014), por lo que es un elemento integrante de la vida cultural y social (Revilla y Olivares, 2019). El uso del arte en el aprendizaje fortalecerá la identidad, donde los estudiantes tendrán una mejor valoración de su propia cultura y la de otras (Dalfsen y Corcuera, 2008). Cabe recordar que toda expresión artística está circunscrita a una cultura, de un contexto vinculado a componentes relacionados a ese entorno, por lo que la actividad artística es necesaria para preservar la cultura de una sociedad, además de la identidad y expresiones de comportamientos requeridos en esta última -como maneras de sentir, pensar y actuar ante las distintas circunstancias que uno se puede encontrar en la vida- (Estévez y Rojas, 2017).

En la XXX Conferencia General de la UNESCO se propuso promover la inclusión de la enseñanza del arte en la educación del niño y del adolescente, en donde uno de sus beneficios es que contribuye a la creación de audiencias de calidad favoreciendo el respeto intercultural. Además, el arte puede ayudar a las personas en riesgo o en exclusión social a una integración más real y profunda, desarrollando en ellas tanto habilidades sociales, corporales y psicológicas, así como un desarrollo verdadero de la autoestima y el autoconcepto (identidad) (García, 2012). No solamente eso, sino que en el 2010 la UNESCO publicó la Agenda de Seúl, en donde en uno de sus objetivos indica la aplicación de la educación artística para solucionar problemas sociales y culturales en el mundo actual, promoviendo la diversidad cultural y el diálogo intercultural (Cabedo-Mas y Arriaga-Sanz, 2016).

Entonces, el arte -como una forma de comunicación, interacción y diálogo respetuoso a fin de fomentar el reconocimiento, auto-reconocimiento, revaloración y reivindicación de las diversas culturas para lograr respeto- para impulsar el diálogo y el reconocimiento de cada uno de los estudiantes es relevante en la educación porque fomenta la empatía e 
identificación entre ellos. La relación que existe entre la empatía con la identificación está tan comprobada que el gobierno de Islandia tomó la medida contra la xenofobia y sexismo pagando a miembros de minorías étnicas y sexuales para que visiten a las familias islandesas con el objetivo de que les cuenten sus historias, con el objetivo de que se familiaricen con su modo de vida, costumbres, etc., con la finalidad de que la percepción del extranjero exótico cambie en la mentalidad de los locales a una figura de una persona con la cual se podrían identificar (zizek, 2011). Esto es algo con lo que concuerda Nussbaum (2011) al indicar que las artes sirven para que las personas puedan ser capaces de ver a otros como entidades que merecen respeto y empatía, saber que cada uno es diferente, con sus propios sentimientos y pensamientos, por lo que se puede promover un debate basado en la razón y la compasión.

Asimismo, el conocimiento del otro es necesario para la formación de la identidad en los estudiantes (Rizo, 2005). El entendimiento del otro es una condición imprescindible para el conocimiento del yo, donde poco a poco el estudiante se coloca dentro de una posición social según su identidad (Alvarez, 1965), algo que es fundamental para la interculturalidad, y que se facilita en clases donde los estudiantes están cohesionados unos con otros. "En una clase cohesionada los alumnos se preocupan unos por otros y se produce un clima favorable que mejora las relaciones, la autoestima, motivación, entre otros aspectos, y puede llegar a generar identificación de los miembros con su grupo" (Arias, Morales, Nouvilas, y Martinez, 2012, p. 187).

Se debe aceptar la idea de comunidad educativa -conjunto de personas naturales o jurídicas que buscan como finalidad la educación- donde los estudiantes actúen unos sobre otros, el profesor no solo debe hablar, sino también escuchar. Las clases se deben convertir en una interacción social (García V. , 1981). La visión de un objeto externo varía de persona en persona porque la percepción está conformada tanto por los genes como por la manera en que el cerebro ha sido moldeado por la experiencia (Pizarro, 2003), por lo que la mutua interacción y conocimiento entre los estudiantes fomenta el respeto a las diferencias, es la única forma de llegar correctamente a la enseñanza de la interculturalidad. Esto es una educación inclusiva, que es cuando los miembros reconocen y entienden la diversidad cultural (Revilla y Olivares, 2019).

Las relaciones en la escuela son paralelas a las que establecerán los estudiantes en su vida social cuando se inserten en la sociedad siendo adultos (García V. , 1981), por lo que es importante que los estudiantes formen su identificación y respeten la de otros durante su formación básica regular, mientras que el colegio requiere fomentar una educación basada en la identidad de cada estudiante, no imponer algo sin considerar a los alumnos y alumnas puesto que eso sería un adoctrinamiento, que deriva en un etnocidio, donde se alega el bienestar del salvaje -que se les considera malos- y se cree que se les puede mejorar transformándolos de manera que se parezcan a ellos (Margulis, 2009). Ante ello, se escoge la escuela para el presente trabajo porque uno de los objetivos primordiales de esta institución es el hacer entender los valores y significados de las diversas culturas en el mundo para que ellos puedan elegir sus valores y concepciones para su vida (Ruiz, 2003). En este contexto, el arte termina siendo una herramienta que puede ser importante para este fin. 
Los colegios emblemáticos en el Perú surgen en el segundo gobierno de Alan García con el Programa Nacional de Recuperación de las Instituciones Públicas Educativas Emblemáticas y Centenarias (Programa de Colegios Emblemáticos), que se ejecutó entre los años 2009 y 2011 por medio del Decreto de Urgencia Nº04-2009 y se suspendió en el 2012. Tuvo como objetivo el de rehabilitar, remodelar y equipar colegios públicos. Durante el periodo mencionado se benefició a 238 colegios (Campana, Velasco, Aguirre, y Guerrero, 2014); de los cuales, 32 se ubican en la ciudad de Lima.

El centro educativo seleccionado para la presente investigación se eligió porque se supo a través de una docente que esta institución en particular no realizaba un buen trabajo en educación intercultural, en donde prácticamente no lo incluían en la enseñanza, a pesar de la existencia de un gran potencial artístico que se podría utilizar como principal herramienta para esta. Además de señalar la poca identificación que tienen sus estudiantes con sus lugares de orígenes, la mayoría de ellos andinos y afrodescendientes, siendo un factor clave para la existencia de ataques racistas entre los propios compañeros. Se decidió escoger como muestra del presente estudio a los estudiantes de quinto y sexto de primaria por conocerse que en este grupo hay una alta incidencia sobre lo último señalado.

\section{ANTECEDENTES}

Juan Carlos Gonzáles-Mohino (2002) propone actividades relacionadas a la educación artística para situar y valorar la diversidad cultural en el arte moderno. El proyecto se llama Más cerca que lejos. Una aproximación a la cultura marroquí a través del papel de la mujer y sus creaciones textiles. Esta iniciativa va dirigida para los estudiantes de primer ciclo de secundaria, entre sus objetivos se destaca el fomentar el respeto y la valoración ante la diversidad cultural al mostrar las diferencias de identidad cultural, y también, rechazar los estereotipos y prejuicios, valorando el diálogo como medio para poder solucionar disputas. Entre las partes de la propuesta se encuentra, primero, el estudio sobre la mujer en el mundo árabe, después se analizan esos resultados con el objetivo de planificar la enseñanza con los conocimientos previos que existen sobre el tema; posteriormente, están las actividades que giran en torno a la danza de velos, los telares marroquíes, y por último, las comparaciones e influencias con el arte moderno. En síntesis, lo que se busca es corregir estereotipos y poder crear nuevas posiciones.

Celia García (2012) defiende la idea de que el arte puede ser utilizado como un medio para integrar a personas excluidas socialmente. En su investigación describe proyectos en arte plástica, música, danza y narrativa que tienen el fin mencionado anteriormente. De los relacionados a la educación artística con la interculturalidad se encuentra el programa Learning Through Art, que tiene como objetivo principal reforzar el currículo escolar con actividades artísticas, en donde además de las unidades didácticas también hay permutas culturales. Cada año hay un intercambio de artistas entre los museos Guggenheim de Bilbao y de Nueva York, es ahí se encuentra la interacción (intercultural). También está el "Leer, una devoción antes que una obligación", que es un programa desarrollado en el CP "San Francisco" en Bilbao, que se ejecuta en un centro donde hay mucha diversidad cultural, existiendo marginación social; se introdujo libros sobre gitanos en los colegios para que los 
estudiantes de este grupo pudieran aceptar su identidad cultural, mientras que los alumnos no gitanos puedan evitar estereotipos sobre estos últimos y los acepten y respeten gracias a conocer las costumbres, las historias, etc., de esta comunidad.

Alfonso Revilla et al. (2015) señalan que la educación intercultural puede ser un acercamiento de culturas por medio del arte, un deseo de saber diferentes maneras de entender la realidad y de afincar conceptos en los diversos niveles de pensamiento. Indican que se debería comprender la diversidad cultural como riqueza, como una posibilidad para poder lograr abrirse a nuevas perspectivas y alternativas, algo que han podido lograr, según ellos, al exhibir piezas y objetos de arte originarios de África subsahariana. El artículo se basa en un seminario que fue la continuación de la exposición Didáctica del objeto plástico ritual del arte africano en el Museo Orús de Utebo (Zaragoza) y en el C.C. José Luis Mosquera de Valladolid en el 2015. Además, la experiencia culminó con el seminario "Promover el diálogo intercultural a través de una mirada al arte africano". Los autores indican que los objetos rituales favorecen al conocimiento de ritos, costumbres y valores resaltantes de la cultura africana, con lo que se fomenta el diálogo y estimula cambios en las personas. Cabe señalar, que las piezas expuestas fueron tallas de maderas, máscaras y objetos tribales de África; además, hubo muestra gastronómica y lectura de poemas con música y complemento audiovisual.

Maribel León e Ismael Corrales (2016) estudian al grupo de baile costarricense de tipo folclórico "Alma Joven", que se convirtió en un conjunto intercultural al integrar coreografías de otros países gracias a la incorporación de compañeras de distintas nacionalidades. Los autores indican que los bailes originarios de los diversos países es una forma de compartir una parte de esos lugares, en donde para conseguir el éxito en un grupo de tipo intercultural es necesario el respeto y la tolerancia. La investigación se centra en las experiencias y vivencias que tuvieron las señoras de origen extranjero (Panamá, Colombia, Ecuador, Cuba y El Salvador, este último fue incluido por una situación única puesto que nunca han tenido de ese país, exactamente fue para realizar un acto con el objetivo de apoyar a una estudiante salvadoreña que se estaba graduando de una universidad en Costa Rica) al integrar a la agrupación. Para cada presentación se eligió una canción para cada país. Lo que señalan los autores es que un grupo de baile folclórico con integrantes de diversas culturas en sus actos muestra lazos de hermandad y demuestra la posibilidad de la existencia de un grupo con esta heterogeneidad. En lo que respecta a "Alma Joven" concluyen que siempre han recibido de buena manera a las personas de diversas nacionalidades, y que además se incentiva a estas nuevas integrantes para que conversen sobre su música folclórica con el objetivo de que se pueda hacer una pieza musical para ponerla al presentar una coreografía sobre su pueblo.

Belén Sirera (2016) estudia la Escolanía del Sagrado Corazón de Rosales, compuesta por alumnos de entre cinco a catorce años, y descubre que en sus trabajos artísticos se utilizan distintos idiomas (principalmente español, inglés, latín, alemán y francés) para sus interpretaciones, no solamente los traducen sino que los contextualizan en el lugar histórico y cultural de origen; además, interpretan diversas obras con diferentes instrumentos (a capella, piano y órgano de tubos, conjunto instrumental y orquesta) y ponen en escena distintos repertorios (música culta y religiosa, musicales y bandas sonoras, música folclórica 
y música pop). En conclusión, según la autora sí se fomenta la interculturalidad porque entre sus características se encuentran la música popular y folclórica como base del saber del pueblo, las adaptaciones musicales de repertorio de otras culturas y la diversidad de lenguas. Todo ello lleva al conocimiento de diversas características artísticas y sociales de diferentes lugares ajenos al propio.

José Ñáñez-Rodríguez y Heidy Castro-Turriago (2016) hacen un estudio de caso sobre los alumnos de 5to grado de la Corporación Colegio San Bonifacio de las Lanzas (Ibagué, Colombia) respecto a la forma en que la educación artística los beneficia en formarse como ciudadanos. Desde el 2007 es que se incentivó a los estudiantes para que se interesaran por el folclor, la tradición y la conservación de sus raíces culturales; motivándolos así a que crearan un sentido de pertenencia e identidad por sus valores culturales gracias a la educación artística. Lo que descubrieron los autores es que gracias a estos proyectos artísticos se está construyendo ciudadanos que reafirman una identificación de tipo cultural, en donde valoran y respetan la tradición, poseen un sentido de pertenencia a su país (por sus ritmos, trajes originarios, costumbres, etc.), pero además para la elaboración de esos eventos se trabajan valores (respeto, tolerancia, confianza, etc.) que aportan en la construcción de sus personalidades. También indican que la formación ciudadana se realiza por el reconocimiento de la propia cultura y la identidad como pueblo, por lo que el arte (ritmos tradicionales, obras musicales, coreografías de danzas, trajes típicos, etc.) visibiliza los elementos ciudadanos. Los autores indican que:

La educación artística que se imparte en el Colegio San Bonifacio de Las Lanzas ha logrado desarrollar aspectos como la sensibilidad, la experiencia estética, el pensamiento creativo y la expresión simbólica, a partir de manifestaciones materiales e inmateriales en contextos interculturales que se expresan a través de los diferentes proyectos artísticos relacionados anteriormente, y que unidos con el arte, la cultura y el patrimonio están contribuyendo a que los individuos se relacionen con la sociedad, se integren en una comunidad, generen identidad, sentido de pertenencia por su ciudad, se unan a otros por vínculos de solidaridad, tolerancia, respeto, se está generando conciencia de grupo, creando vínculos de afecto y lealtad a su ciudad formada a partir de una historia y una tradición cultural particular (p 164).

Alfonso Revilla y Pilar Olivares (2019) analizan la posibilidad de poder incluir el arte africano en la educación escolar de España como un modo de plantear la interculturalidad como parte de la sociedad. Indican que un proyecto de carácter intercultural debe tratar de hacer reflexionar sobre el racismo y la discriminación relacionada a ella, a través de poner al Otro como el iniciador, al comprenderlo y al visualizarlo, del diálogo entre culturas. Los autores ejemplifican con tres exposiciones relacionadas al arte negroafricano la aplicación de la didáctica de este tipo de arte: 1) Máscaras africanas, el rostro de los espíritus (exposiciones sobre la educación plástica), 2) Ver Áfricas (propuesta para la educación artística sobre un acercamiento al continente africano), y 3) Una parte de África a través del arte (exposición sobre la interculturalidad en la educación por medio del arte). Cabe señalar que los tres eventos se realizaron en el 2018. 
Mar Ronchera y Auxiliadora Sales (2020) utilizan el método autoetnográfico y han investigado en el CESAL: Centro Educativo y Social de Alcalà de Xivert (España) colaboración de 18 mujeres que participan en el taller de "empoderamiento y adaptación a la sociedad de acogida de mujeres magrebís"-, en el Centro Cultural Aminata de Gandiol (Senegal) y la Residencia Artística Dëkandoo de Gandiol (Senegal). De estos dos últimos lugares las personas informantes son habitantes del pueblo de Gandiol e integrantes y voluntarios del equipo de Hahatay. Entre los resultados más destacados sobre la interculturalidad desde el arte está el espacio en el centro cultural Aminata de Gandiol donde se muestra la polivalencia de los objetivos de tipo residuales, principalmente de plástico, como la bisutería, materiales escolares, decoraciones, etc., todos hechos con residuos; pero, además, el hecho de que recojan basura de las calles ayuda a concientizar a los ciudadanos sobre este tema. Sumado a ello, las autoras señalan que la construcción comunitaria de ambos centros culturales (Aminata y Dëkandoo) exhiben el fortalecimiento de proyectos de tipos colaborativos, la producción sobre cultura, experiencias estéticas, etc., gracias al arte. Entre sus postulados aducen que los encuentros de tipo interculturales ayudan a eliminar prejuicios y a auto construirse debido al contacto que se tiene con el resto de las personas, porque para encontrarse es necesario identificar al otro sujeto en la relación que se ha formado.

María Hernández (2020) señala que la educación artística puede ser una herramienta útil para introducir la educación intercultural en las aulas de clases. La autora analiza los conocimientos sobre interculturalidad que tienen los estudiantes del Grado en Educación Primaria (del curso académico 2018/2019) de la Universidad de Sevilla por medio de 210 encuestas respondidas. Lo que descubre es que estos alumnos reconocen no haber tenido formación sobre la educación intercultural, lo que significa que hay un déficit en la formación sobre este tema. Ante ello, los propios encuestados se expresan inseguros sobre la gestión en diversidad cultural que van a tener en el futuro en las aulas de clases, incluso la mayoría de ellos piensa negativamente cuando se hace referencia a la inmigración; por otro lado, reconocen la riqueza que supone la diversidad cultural para el aula. También, confiesan que la educación artística es una herramienta considerada útil para poder transformar socialmente a las personas, este pensamiento es gracias a lo que hacen los profesores de educación artística en las universidades.

\section{MARCO LEGAL}

Sobre el problema prioritario de la identidad, en las leyes peruanas se encuentra:

Ley $N^{\circ} 27337$ Código de los Niños y Adolescentes (1993-2000): Considera la igualdad de oportunidades y la no discriminación a que tiene derecho todo niño y adolescente sin distinción de sexo.

Ley $\mathrm{N}^{\circ}$ 28044, Ley General de Educación (2006)- artículo $10^{\circ}$ y $19^{\circ}$ : La educación peruana tiene a la persona como centro y agente fundamental del proceso educativo. Se sustenta en el principio de inclusión, que incorpora a las personas con discapacidad, grupos sociales excluidos, marginados y vulnerables, especialmente en el ámbito rural, sin distinción de etnia, religión, sexo u otra causa de discriminación, contribuyendo así a la eliminación de la pobreza, la exclusión y las desigualdades. 
Ley $\mathrm{N}^{\circ} 27270$, Ley contra actos de Discriminación (2000): Establece que la oferta de empleo y el acceso a centros de formación educativa no podrán contener requisitos que constituyan discriminación, anulación o alteración de la igualdad de oportunidades o de trato; e incluye sanciones a las personas que incurran en estas conductas por parte del Ministerio de Trabajo y Promoción Social y Educación

Constitución Política del Perú 1993: artículo 2, inciso 2: Toda persona tiene derecho a la igualdad ante la ley. Nadie debe ser discriminado por motivos de origen, raza, sexo, idioma, religión, opinión, condición económica o de cualquier otra índole.

Decreto Supremo N ${ }^{\circ}$ 001-2012-MIMP, que aprueba el Plan Nacional de Acción por la Infancia y Adolescencia 2012-2021. Que, el Plan Nacional señalado dispone la agenda sobre la cual el Perú debe trabajar hacia el año 2021, a fin de generar condiciones que garanticen a nuestras niñas, niños y adolescentes ejercer plenamente sus derechos y acceder a oportunidades, con equidad y sin discriminación, para un desarrollo integral y participativo en su entorno familiar, escolar y comunitario.

Sobre lo que se quiere lograr:

Resolución Ministerial №339-2014-MC, que aprueba el instrumento "Orientaciones para la implementación de Políticas Públicas para la Población Afroperuana”. En el Perú es vital que se reconozca plenamente que la cultura afroperuana es parte del universo cultural peruano, es decir, que forma parte indesligable de su identidad como nación. Asimismo, tomando en cuenta la fragilidad actual de las tradiciones orales y conocimientos ancestrales, es necesario que se implementen medidas para garantizar su conservación y puesta en valor. En ese sentido, es fundamental establecer medidas de salvaguardia que garanticen la conservación, la revaloración y la puesta en valor de las diferentes expresiones culturales afroperuanas. Garantizar los derechos culturales de la población afroperuana implica mejorar las condiciones para la producción de bienes y servicios culturales, asegurar su igualdad en el acceso a las expresiones artísticas y apoyar la creación, expresión y difusión de las mismas.

Resolución Ministerial $\mathrm{N}^{\circ}$ 143-2015-MC, que aprueba el documento denominado: "Diálogo Intercultural: pautas para un mejor diálogo en contexto de diversidad cultural". Busca promover la comunicación con pertinencia cultural elaborando una agenda consensuada entre los actores de las instituciones asumiendo sobre los resultados del diálogo.

Resolución Viceministerial $\mathrm{N}^{\circ}$ 001-2015-VMI-MC, que aprueba el documento denominado: "Orientaciones para el fomento y la protección de la diversidad cultural". La diversidad cultural es uno de los activos más importantes de nuestra sociedad global. Su reconocimiento fomenta que los derechos humanos se garanticen de un modo más efectivo, pues permite que se tome en cuenta la pluralidad de experiencias, visiones, expectativas y culturas de ciudadanos/as y pueblos al momento de gestionar la cultura y la política pública de una sociedad. 
Declaración Universal de la Unesco sobre la Diversidad Cultural (UNESCO). 2 de noviembre de 2001. La cultura debe ser considerada el conjunto de los rasgos distintivos espirituales y materiales, intelectuales y afectivos que caracterizan a una sociedad o a un grupo social y que abarca, además de las artes y las letras, los modos de vida, las maneras de vivir juntos, los sistemas de valores, las tradiciones y las creencias.

Convención Internacional sobre la Eliminación de todas las formas de Discriminación Racial (CDB-ONU) - Fue adoptada por la Asamblea General de las Naciones Unidas el 21 de diciembre de 1965, y entró en vigor el 4 de enero de 1969, luego de alcanzado el número de ratificaciones necesario. Garantizar el derecho a la seguridad personal y a la protección del Estado contra todo acto de violencia o atentado contra la integridad personal cometido por funcionarios públicos o por cualquier individuo, grupo o institución.

Sobre los responsables:

Ley N²2844, Ley General de Educación (2006):

Articulo 68 inciso E, I, J: funciones de la IE que el director está encargado de realizar (artículo 55 inciso A,). Artículo 73 Y 74 donde establece las funciones de la UGEL: promover y ejecutar estrategias y programas efectivos de alfabetización, de acuerdo con las características socio-culturales y lingüísticas de cada localidad.

Ley № 27741, Ley que establece la Política Educativa en materia de Derechos Humanos y crea un Plan Nacional para su difusión y enseñanza. Se sustenta en el Decreto Supremo № 010-2012-ED. Reglamento de la Ley № 29719, Ley que promueve la convivencia sin violencia en las instituciones educativas.

Ley Orgánica de Municipalidades No. 27972 (2003). Educación, cultura, recreación y promoción social: artículo 28: crear, organizar y mantener bibliotecas municipales. Establecer y conservar parque zoológico, jardines botánicos.

Plan Estratégico de la municipalidad: 2018-2020. Quienes definen los resultados que la entidad espera lograr en las condiciones de vida a la que atiende y en sus condiciones internas en cumplimiento con sus funciones administrativas determinadas por la Ley Orgánica.

Normas y reglamentos de la UGEL

UGEL es responsable de la gestión de la educación básica regular, especial, alternativa y técnico-productiva y de supervisar el servicio educativo brindado por las instituciones educativas.

R.V.M. № 0022-2007-ED, Aprueban "Normas para el Fortalecimiento de la Convivencia y Disciplina Escolar, el Uso Adecuado del Tiempo y la Formación Ciudadana, Cívica y Patriótica de los Estudiantes de las Instituciones y Programas de la Educación Básica Regular". 
Resolución Directoral № 180-2008-ED, Aprueba los Lineamientos Educativos y Orientaciones Pedagógicas para la Educación Sexual Integral para Profesores y Tutores de la Educación Básica Regular.

Resolución Directoral № 0343-2010-ED, Normas para el desarrollo de las acciones de Tutoría y Orientación Educativa en las Direcciones Regionales de Educación, Unidades de Gestión Educativa Local e Instituciones Educativas.

Directiva № 001-2006-VMGP/DITOE, Normas para el desarrollo de la Campaña de sensibilización y promoción "Tengo Derecho al Buen Trato" que incluye a la Convivencia Escolar Democrática.

\section{CONCEPTOS BÁSICOS}

El arte es una forma de expresión para transmitir emociones y sentimientos a los espectadores, pero también puede ser una simple manera de comunicación por parte de los creadores para mostrar distintos aspectos que deseen, por ejemplo, su personalidad, protestas, realidades socioeconómicas y políticas, etc. Entre sus funciones se encuentra la de poder acercar a las personas a distintas realidades y la identificación del otro (García C. , 2012). En este caso se va a concebir el arte como toda expresión cultural, que incluya: baile, danza, esculturas, fotografías, prácticas ancestrales, pintura, dibujo y canto. En ese mismo sentido, por medio del Congreso Regional de Formación Artística y Cultural para la región de América Latina y el Caribe del 2007 se definió como educación artística y cultural "el campo de conocimiento, prácticas y emprendimiento que busca potenciar y desarrollar la sensibilidad, la experiencia estética, el pensamiento creativo y la expresión simbólica, a partir de manifestaciones materiales e inmateriales en contextos interculturales que se expresan desde lo sonoro, lo visual, lo corporal y lo literario, teniendo presentes nuestros modos de relacionarnos con el arte, la cultura y el patrimonio" (Ñáñez-Rodríguez y Castro-Turriago, 2016, p. 157).

La cultura es un sistema de conocimiento constituido por elementos interactivos que se comparten y transmiten por las personas que se identifican con ello, lo que genera una realidad con la que podemos proveer de sentido a nuestro comportamiento (Aguirre, 1997). Según el informe de Desarrollo Humano de Chile del 2002, señala que la cultura es la práctica y el imaginario de la vida en común (Rey, 2007). Mientras que la interculturalidad es un proceso histórico que se caracteriza por la coexistencia de las distintas culturas en un plano de igualdad que no solo se limita a la etnia o cultura, sino también a la de clase. Hay un intento de conocimiento y aceptación, por lo que prima la inclusión y respeto, superando la simple tolerancia (Alavez, 2014) (Mondragón, 2010). En esa misma línea, el diálogo intercultural consiste en un intercambio de opiniones en un marco de respeto y entendimiento mutuo entre personas y grupos provenientes de culturas diferentes (Consejo de Europa , 2008). Asimismo, la diversidad cultural se divide en dos acercamientos: dentro de los estados y entre los estados. En el primero está ligado al fenómeno de inmigración y a cualquier individuo que, en su conjunto, con personas de su misma cultura, tiene el potencial de construir otra nación u otra forma de identidad. Mientras que la diversidad cultural entre estados se da con el intercambio que hay entre estados, naciones y/o culturas en el mercado, además de la posibilidad de cada uno de ellos para preservar y promocionar sus propias culturas (Hernández, 2008). 
Los afroperuanos son los descendientes africanos que han nacido en el Perú. Se define por su color de piel, los antepasados y autopercepción (Miranda, Zorrilla , y Arellano, 2013). Mientras que lo étnico proviene del griego etnos, que significa pueblo. Se utiliza para referirse a grupos considerados una minoría dentro de un Estado. Es una construcción social para identificar las diferencias e igualdad entre "ellos" con el "nosotros" (Lamus, 2012). Mientras que los andinos son las personas originarias de Colombia, Ecuador, Perú, y Bolivia. En este caso, debido al problema de amplitud que tiene solamente se está considerando a las personas de Perú.

\section{METODOLOGÍA}

Es una investigación de caso de tipo cualitativa. La investigación de caso hace referencia al estudio del fenómeno -en este estudio a la educación intercultural- en su contexto real (Yin, 1994), por lo que se utilizaron como métodos para la recopilación de información la revisión documentaria, las entrevistas y la observación a través de visitas que se realizaron tanto al colegio como al Cerro San Cosme y Cerro El Pino, zonas de donde provienen la mayoría de alumnos, que comenzó en septiembre del 2019 y que culminó en diciembre del mismo año. Cabe recordar que el estudio se centra en los estudiantes de 5to y 6to de primaria, por lo que la información se basa en esta muestra. Por otro lado, es necesario señalar que el presente estudio es de tipo cualitativo porque se estudia la realidad cómo ocurren en su contexto natural, recopilando información que proviene de las personas implicadas (Blasco y Pérez, 2007) y que no son datos numéricos.

Para la realización del análisis interno se apeló a la revisión documentaria, que se basó en el diagnóstico situacional que hizo la propia institución educativa entre los años 20182019. Sumado a ello, se hizo diez visitas al colegio, en donde se efectuó la observación de las clases y se entrevistaron a 15 estudiantes de los grados ya indicados anteriormente, además de diez docentes que enseñan en todo el nivel primaria. La cantidad de la muestra fue determinada por el punto de saturación, al evidenciar que se obtenían respuestas repetidas y que no se conseguía información nueva, por lo que se decidió terminar con el número de las entrevistas.

Por otro lado, para realizar el análisis externo se recabó y consolidó la información vertida por las y los entrevistados/as (docentes, personal administrativo) y con el apoyo de la Unidad de Estadística y Monitoreo de la Unidad de Gestión Educativa Local, y se pudo visibilizar con exactitud las zonas de origen de las familias de los estudiantes y los lugares donde residen en el momento de la investigación. Una vez extraído esos datos se corroboró que la mayoría de los estudiantes de los grados seleccionados son de procedencia andina y que en la actualidad viven en el Cerro San Cosme y el Cerro el Pino; es por esta razón que se realizaron diez visitas a estos lugares, donde no solamente se aplicó la observación para recabar información sobre las actividades artísticas en el lugar, sino también se entrevistó a un docente de break dance (Cerro San Cosme), a un estudiante de este mismo profesor (Cerro San Cosme), a dos madres artesanas (una de Cerro San Cosme y otra del Cerro El Pino), a dos líderes juveniles de la comunidad afroperuana (Cerro El Pino) y a un docente de arpa (Cerro El Pino). 
Para el diseño de la propuesta del proyecto se ha basado principalmente en lo señalado por Román (1999), quien indica que primeramente se debe analizar la situación problemática, después es necesario identificar a los beneficiarios de la intervención y a los actores claves, definir las estrategias para solucionar el problema, justificar la intervención, mencionar los objetivos del proyecto, los recursos para llevarlo a cabo, los resultados que se esperan obtener, expresar las actividades que se van realizar y el tiempo de la intervención.

\section{RESULTADOS}

\section{Análisis externo}

La mayoría de los alumnos de 5to y 6to de primaria del colegio emblemático estudiado provienen de las zonas del Cerro San Cosme y Cerro El Pino, ambos ubicados en el distrito de La Victoria. Según el último Censo (2017), la población que radica en ambos lugares mencionadas tiene una población predominantemente joven (de 15 a 29 años) que abarcan un $39 \%$ del total, por otra parte, hay un mayor porcentaje de hombres (52\%) frente al de mujeres $(47,9 \%)$. Se precisa también que la mayoría de los habitantes de la zona son hijas e hijos y nietos/as de los primeros migrantes (80\%) y que solamente el $16,7 \%$ de personas no vivían en las zonas hace cinco años. Además, gran parte de los estudiantes que habitan en el Cerro San Cosme provienen de familias migrantes en su mayoría de Huancayo, Puno, Cajamarca y Ancash; mientras que en el Cerro El Pino las familias de los estudiantes son principalmente de Puno y Huancavelica, además existen familias auto-identificadas como afro descendiente. Bajo ese contexto se puede apreciar que hay una gran población de estudiantes que provienen de culturas, costumbres, y grupos étnicos distintos.

En el aspecto cultural la población del Cerro San Cosme y del Cerro El Pino es de tradición andina, precisamente por ser originarios de ahí, y que entró en conflicto desde la década del 70 con la nueva urbanización residencial 12 de octubre que se ubica del lado izquierdo del cerro hacia la av. México, que por su origen no migrante sino más bien de la clase media pauperizada de lima tenía como manifestación cultural la música criolla por excelencia, formándose dos zonas muy diferenciadas culturalmente. Esa división es tan importante que es una calle lo que estableció el límite, la calle se llama Sebastián Barranca. Aparte del mundo culturalmente diferente también se produjo lo político, que ha ido disminuyendo en los últimos tiempos.

En lo que se refiere a la música el Cerro San Cosme ha tenido desde sus inicios como máxima expresión de su identidad cultural el huayno, pero después fue virando a la chicha, que se volvió muy popular en el lugar debido al cantante 'Chacalón'. El Cerro también cuenta con un local donde antes las ONG's organizaban actividades artísticas como cajón, teatro, danza, entre otros; pero dejó de hacerse. Actualmente, depende de la iniciativa propia de los habitantes para organizar actividades; una de ellas es el break dance, que cuenta entre 35 a 40 alumnos.

Mientras que en El Pino se reúnen afroperuanos todos los fines de semanas en los parques para cantar y bailar música afro, y a veces salsa, creando un espacio de convivencia a través del arte. Además, El Pino cuenta con un local comunal, donde se enseña música de manera esporádica, como el arpa. Sumado a esto, hay jóvenes que se reúnen para hacer 
grafitis en las calles. Cabe indicar que la International Society for Music Education (ISME) reconoce la capacidad de la música para promover a que las personas puedan aprender y entender sobre la interculturalidad existente (Cabedo-Mas y Arriaga-Sanz, 2016).

En el distrito donde se encuentran ambos cerros existen también agrupaciones de índole social y artísticas que promueven el arte, la cultura, el teatro, la danza y la pintura como formas de generar espacios de concertación y prevención de la delincuencia juvenil. Estos activos culturales pertenecen al programa de Cultura Viva Comunitaria (MML) en la Localidad de Lima Centro, las cuales están inscritas formalmente con la siguiente denominación: Asociación Cultural "El Averno", EPA (Educación, protagonismo y arte), Portavoz Perú (acción y arte), Teatro Vivo - arte para a transformación social y la Asociación Cultural Llaqta.

Velarde (2013) estudió la labor de Teatro Vivo y descubrió que se utilizó principalmente el arte - técnicas de arte que posibilitaron a los beneficiarios explorar introspectivamente lo trabajado por sesiones con actividades relacionadas al teatro, circo y recitales- y el juego -juegos tradicionales que se basaron según la identidad cultural visibilizados a través de sus expresiones barriales o comunales- para el desarrollo y fortalecimiento de los adolescentes. Lo que resultó fue que estos últimos pudieron abrirse y expresarse sobre el tema, por lo que el taller funcionó para que lograran tener la confianza suficiente para compartir sus opiniones y experiencias sobre la temática en cuestión. Cada uno de los participantes escuchaba y era escuchado cuando hablaba, por lo que se generó un respeto a lo que el otro dijera; debatieron sobre la problemática, lo que significa que el arte y el juego logró que se interesaran en el tema; además de que se construyeron consensos; es decir, hubo tolerancia y respeto en la diversidad de pensamientos en el tema en cuestión. Con lo que se concluye que el resultado fue muy positivo y que el arte sirvió para informar y sensibilizar a los beneficiarios sobre el tema.

Es importante mencionar también que una de las fortalezas identificadas en la zona de intervención es que existen mujeres artesanas, que tejen, cortan y fabrican carteras, polos y gorros de forma tradicional, que luego venden y ofrecen en los mercados de manera informal, asimismo se han identificado grupos de adolescentes afroperuanos que bailan y cantan todos los fines de semana en las faldas del Cerro El Pino, mientras que los adultos cantan tocan cajón cada domingo en las diversas lozas deportivas tanto del Cerro San Cosme como del Cerro El Pino. Cabe señalar que estas formas de manifestación cultural no están agrupadas, ni formalizadas es parte del devenir diario del distrito (Miranda, Zorrilla y Arellano, 2013).

\section{Análisis interno}

El colegio es mixto, alberga a un aproximado de 1500 estudiantes, en donde la mayoría (95\%) son de ascendencia andina o afroperuana. El centro educativo enseña todos los niveles de la educación básica regular: nivel inicial, primaria y secundaria; de los cuales, un poco menos de la mitad son de primaria, exactamente 700.

En base al documento del análisis situacional del centro educativo se pudo observar que los estudiantes poseen un bajo rendimiento en los estudios, principalmente causados por 
una baja motivación y malos hábitos en la alimentación. Pero también se caracterizan por vivir en hogares disfuncionales -donde predomina principalmente la violencia- y por ser violentos en el colegio -maltrato entre pares-. Por otro lado, se ha descubierto que los docentes y el personal administrativo poseen una escasa identidad institucional que se traduce, sobre todo, en la impuntualidad y que existen conflictos entre ellos en donde forman grupos y subgrupos que rivalizan unos con otros.

A través de las entrevistas es que se evidencia que los docentes desconocen sobre el enfoque intercultural en el ámbito educativo, a pesar de tenerlo estipulado como eje transversal en el currículo nacional, pues solo se dedican a avanzar con sus sesiones pedagógicas y cumplir con su dictado de clases. Refieren además que nunca han generado espacios para el intercambio de conocimientos y costumbres de acuerdo al lugar de procedencia; por ello, cuando ingresa un nuevo estudiante al aula, solo menciona sus datos personales, no hay interés en conocer un poco más al alumno/a, como saber sobre sus raíces u orígenes; es decir, no se fomenta la auto-identificación ni el reconocimiento de los estudiantes dentro y fuera del aula.

En cuanto a los estudiantes, con la información recogida a través de las entrevistas se puede sintetizar en que no existe una adecuada auto-identificación, ni reconocimiento de las diversas formas de vida y costumbres, muy por el contrario se evidencia un desconocimiento y desapego prolongado a consecuencia de los diversos insultos racistas por origen étnico, como los relacionados al ser catalogado como "serrano" o "cholo", lo mismo sucede con los estudiantes que provienen de familias afroperuanas, quienes son marginados o estereotipados por su color de piel; y ante ello, los docentes no aplican ningún mecanismo de diálogo, ni optan por ninguna acción para hacerles frente a ello, y en lo general asocian esas conductas a la indisciplina, lejos de entender que esas conductas ameritan darle una mirada amplia en cuanto a la diversidad cultural que existe en el colegio, y bajo ello, fomentar espacios de reflexión y diálogo.

El proyecto tiene como público objetivo a niñas y niños del quinto y sexto grado de primaria, es decir un total de 120 estudiantes, donde sus edades fluctúan entre 11 y 12 años; de los cuales, el $60 \%$ son niñas y $40 \%$ son niños, lo que conlleva a considerar que existe una alta incidencia de mujeres que acceden a la educación y son parte del sistema educativo.

\section{Propuesta}

Primero indicar que este es un proyecto social, lo que significa que es una acción que tiene como objetivo generar cambios en una realidad que envuelve y afecta a un grupo social (Martinic citado de Román, 1999). Se ha decidido entrelazar el arte con la perspectiva cultural, pues según los datos obtenidos existe una gran parte de estudiantes de la comunidad educativa que provienen de familias migrantes y con ascendencia afroperuana y andina, por lo que el arte es una herramienta que permitirá conocer las diferencias culturales y étnicas en que se desenvuelven las y los estudiantes, además de comprender las necesidades e intereses diferenciados, a fin de formular medidas de cambio personal y familiar, que no solo contribuyan a mejorar la mejora de aprendizajes, sino que también aporten al 
reconocimiento, autoconocimiento, reivindicación y revalorización de la diversidad cultural dentro de su desarrollo social.

\section{Objetivo del proyecto}

La implementación de la enseñanza del arte como una forma de revitalizar las prácticas culturales y revalorar costumbres, tradiciones, reconocimiento $\mathrm{y}$ autoreconocimiento de la identidad cultural. Esto debido a las necesidades educativas de las y los escolares del 5to y 6to grado del nivel primario, quienes requieren lograr aprendizajes pertinentes en marco del enfoque intercultural; aprendizajes fundamentales a partir de la diversidad cultural como riquezas y potencialidades para la construcción de una auténtica convivencia - democrática e intercultural.

El sostenimiento del proyecto se sustenta en los siguientes dos puntos:

a) La articulación de la tutoría con los planes nacionales; es decir, las actividades artísticas estarán consignadas dentro de las horas de tutoría, que ayudará a fortalecer el objetivo de generar un adecuado clima escolar.

b) La convivencia democrática e intercultural: no solo se fortalecerá el diálogo respetuoso, la revalorización de las culturas ancestrales de las familias de las y los niños del centro educativo, sino también se reforzarán patrones de cultura que involucra la participación de las autoridades educativas y las organizaciones internas tales como los municipios escolares, los policías escolares, entre otros que servirán como facilitadores al momento de ejecutar las acciones y actividades propias del proyecto. 


\section{Cuadro 1}

Estrategias de intervención

\begin{tabular}{|c|c|c|c|c|c|c|}
\hline \multirow[b]{2}{*}{ COMPONENTES } & \multirow{2}{*}{$\begin{array}{l}\text { ¿CUÁL ES EL } \\
\text { PROBLEMA } \\
\text { PRIORIZADO? }\end{array}$} & \multirow[b]{2}{*}{$\begin{array}{l}\text { ¿QUÉ ACTIVIDADES } \\
\text { SE REALIZARÁN? }\end{array}$} & \multirow[b]{2}{*}{$\begin{array}{l}\text { ¿QUÉ SE QUIERE LOGRAR? } \\
\text { METAS }\end{array}$} & \multicolumn{3}{|c|}{ ¿QUIÉN ES EL RESPONSABLE? } \\
\hline & & & & $\begin{array}{l}\text { SECTOR U } \\
\text { ORGANISMO }\end{array}$ & $\begin{array}{l}\text { GOBIERNO } \\
\text { REGIONAL }\end{array}$ & $\begin{array}{l}\text { GOBIERNO } \\
\text { LOCAL } \\
\text { PROVINCIAL }\end{array}$ \\
\hline NORMATIVA & $\begin{array}{l}\text { Clima escolar no } \\
\text { favorable para el logro } \\
\text { de los aprendizajes }\end{array}$ & Educación formativa & $\begin{array}{l}\text { Conocimiento y respeto de la } \\
\text { diversidad cultural por parte } \\
\text { de los estudiantes. }\end{array}$ & $\begin{array}{l}\text { Dirección } \\
\text { académica y } \\
\text { docentes }\end{array}$ & Lima & Lima \\
\hline $\begin{array}{l}\text { RECURSOS } \\
\text { HUMANOS }\end{array}$ & $\begin{array}{l}\text { Docentes no fomentan } \\
\text { la educación } \\
\text { intercultural. }\end{array}$ & $\begin{array}{l}\text { Sistema de gestión } \\
\text { institucional }\end{array}$ & $\begin{array}{l}\text { Aplicación de técnicas } \\
\text { pedagógicas por parte de los } \\
\text { docentes. }\end{array}$ & $\begin{array}{l}\text { Dirección } \\
\text { académica }\end{array}$ & Lima & Lima \\
\hline $\begin{array}{l}\text { RECURSOS } \\
\text { ECONÓMICOS }\end{array}$ & $\begin{array}{l}\text { Insuficiente recursos } \\
\text { económicos. }\end{array}$ & $\begin{array}{l}\text { Mejora en la } \\
\text { distribución de } \\
\text { recursos económicos. }\end{array}$ & $\begin{array}{l}\text { Asignación de mayor } \\
\text { presupuesto para fomentar el } \\
\text { arte como mecanismo } \\
\text { educativo intercultural. }\end{array}$ & $\begin{array}{l}\text { APAFA y } \\
\text { dirección } \\
\text { académica }\end{array}$ & Lima & Lima \\
\hline
\end{tabular}

Fuente de elaboración: propia 


\section{Cuadro 2}

\begin{tabular}{|c|c|c|c|c|c|c|c|c|}
\hline $\begin{array}{l}\text { COMPONENTES } \\
\text { PRIORIZADOS }\end{array}$ & ACTIVIDAD & OBJETIVOS & RESULTADOS & BENEFICIARIOS & ACTORES & ESTRATEGIAS & RECURSOS & FECHAS \\
\hline \multirow[b]{2}{*}{ NORMATIVA } & \multirow{2}{*}{$\begin{array}{l}\text { Elaborar y } \\
\text { ejecutar } \\
\text { protocolos } \\
\text { para un clima } \\
\text { escolar } \\
\text { favorable al } \\
\text { logro de los } \\
\text { aprendizajes. }\end{array}$} & \multirow{2}{*}{$\begin{array}{l}\text { Mejorar la } \\
\text { convivencia } \\
\text { estudiantil. }\end{array}$} & \multirow{2}{*}{$\begin{array}{l}\text { Disminución de } \\
\text { un } 80 \% \text { de los } \\
\text { casos de bullying } \\
\text { (agresiones y } \\
\text { discriminación) } \\
\text { relacionados a } \\
\text { temas étnicos- } \\
\text { culturales. }\end{array}$} & \multirow{2}{*}{$\begin{array}{l}\text { Estudiantes, en el } \\
\text { rendimiento } \\
\text { escolar debido a } \\
\text { una mejor } \\
\text { convivencia con } \\
\text { sus compañeros. } \\
\text { Conocimiento de } \\
\text { protocolos gracias } \\
\text { a talleres y juego. }\end{array}$} & \multirow{2}{*}{$\begin{array}{l}\text { Estudiantes } \\
\text { Docente } \\
\text { Padres de } \\
\text { familia } \\
\text { Director }\end{array}$} & $\begin{array}{l}\text { Seguimiento de los } \\
\text { avances para la } \\
\text { elaboración de los } \\
\text { protocolos }\end{array}$ & $\begin{array}{l}\text { - Tiempo } \\
\text { - Recurso } \\
\text { humano } \\
\text { - Materiales }\end{array}$ & \multirow{2}{*}{$\begin{array}{l}\text { Previo al } \\
\text { inicio del } \\
\text { año escolar } \\
\text { (enero a } \\
\text { marzo) }\end{array}$} \\
\hline & & & & & & $\begin{array}{l}\text { Monitoreo del } \\
\text { cumplimiento de } \\
\text { los efectos } \\
\text { deseados por la } \\
\text { ejecución de los } \\
\text { protocolos. }\end{array}$ & $\begin{array}{r}\text { - Recurso } \\
\text { humano }\end{array}$ & \\
\hline \multirow{2}{*}{$\begin{array}{l}\text { RECURSOS } \\
\text { HUMANOS }\end{array}$} & \multirow{2}{*}{$\begin{array}{l}\text { Medidas de } \\
\text { supervisión } \\
\text { para que los } \\
\text { docentes } \\
\text { apliquen la } \\
\text { educación } \\
\text { intercultural. }\end{array}$} & \multirow{2}{*}{$\begin{array}{l}\text { Elevar los } \\
\text { niveles de } \\
\text { conocimiento } \\
\text { y respeto por } \\
\text { parte de los } \\
\text { estudiantes a } \\
\text { la diversidad } \\
\text { cultural. }\end{array}$} & \multirow{2}{*}{$\begin{array}{l}\text { Un } 60 \% \text { de los } \\
\text { estudiantes } \\
\text { poseen una } \\
\text { mayor valoración } \\
\text { de las culturas de } \\
\text { donde provienen } \\
\text { sus familias y las } \\
\text { de sus } \\
\text { compañeros. }\end{array}$} & \multirow{2}{*}{$\begin{array}{l}\text { Estudiantes, en la } \\
\text { construcción de su } \\
\text { auto-identificación } \\
\text { gracias al } \\
\text { conocimiento de } \\
\text { las distintas } \\
\text { identidades } \\
\text { culturales. } \\
\text { Espacios dentro de } \\
\text { las clases para } \\
\text { participación y } \\
\text { diálogo entre } \\
\text { estudiantes. }\end{array}$} & \multirow{2}{*}{$\begin{array}{l}\text { Especialista } \\
\text { Estudiantes } \\
\text { Docentes }\end{array}$} & $\begin{array}{l}\text { Seguimiento al } \\
\text { cumplimiento de la } \\
\text { educación } \\
\text { intercultural en las } \\
\text { clases de los } \\
\text { docentes. }\end{array}$ & $\begin{array}{r}\text { - Recurso } \\
\text { humano }\end{array}$ & \multirow{2}{*}{$\begin{array}{l}\text { Durante el } \\
\text { año escolar } \\
\text { (marzo a } \\
\text { julio y } \\
\text { agosto a } \\
\text { diciembre) }\end{array}$} \\
\hline & & & & & & $\begin{array}{l}\text { Evaluación a los } \\
\text { estudiantes para } \\
\text { conocer el avance } \\
\text { en conocimiento y } \\
\text { respeto a la } \\
\text { diversidad cultural. }\end{array}$ & $\begin{array}{l}\text { - Tiempo } \\
\text { - Recurso } \\
\text { humano }\end{array}$ & \\
\hline \multirow{2}{*}{$\begin{array}{l}\text { RECURSOS } \\
\text { ECONÓMICOS }\end{array}$} & \multirow{2}{*}{$\begin{array}{l}\text { Reducir } \\
\text { costos para } \\
\text { asignar } \\
\text { mayor } \\
\text { presupuesto } \\
\text { al fomento } \\
\text { del arte. }\end{array}$} & \multirow{2}{*}{$\begin{array}{l}\text { Utilizar el } \\
\text { arte como } \\
\text { herramienta } \\
\text { principal en } \\
\text { el fomento de } \\
\text { la } \\
\text { interculturali } \\
\text { dad }\end{array}$} & \multirow{2}{*}{$\begin{array}{l}\text { El } 70 \% \text { de los } \\
\text { estudiantes } \\
\text { participan en } \\
\text { actividades } \\
\text { relacionadas al } \\
\text { arte de manera } \\
\text { voluntaria. }\end{array}$} & \multirow{2}{*}{$\begin{array}{lr}\text { Estudiantes, en } \\
\text { utilizar el arte } \\
\text { como medio de } \\
\text { conocimiento } \text { y } \\
\text { expresión de su } \\
\text { identidad. Abrir } \\
\text { diversidad de } \\
\text { opciones artísticas. }\end{array}$} & \multirow{2}{*}{$\begin{array}{l}\text { Docentes } \\
\text { Estudiantes } \\
\text { Personal } \\
\text { administrat } \\
\text { ivo } \\
\text { Director }\end{array}$} & $\begin{array}{l}\text { Elaboración de una } \\
\text { auditoría para } \\
\text { reasignar gastos. }\end{array}$ & $\begin{array}{l}\text { - Tiempo } \\
\text { - Recurso } \\
\text { humano } \\
\text { - Recurso } \\
\text { económico }\end{array}$ & \multirow{2}{*}{$\begin{array}{l}\text { Durante el } \\
\text { año escolar, } \\
\text { constante/ } \\
\text { paulatino. }\end{array}$} \\
\hline & & & & & & $\begin{array}{l}\text { Seguimiento a la } \\
\text { participación de los } \\
\text { estudiantes en los } \\
\text { talleres artísticos. }\end{array}$ & $\begin{array}{r}\text { - Recurso } \\
\text { humano }\end{array}$ & \\
\hline
\end{tabular}


El tutor/a para desarrollar su labor deberá reunir el perfil requerido y ser capacitado en Tutoría y Orientación Educativa, estrategias socio-emocionales y atender las necesidades y preocupaciones de las y los estudiantes individual y grupal contando con las siguientes herramientas:

\section{Instrumentos}

- Ficha diagnóstica.

- Funciones y Perfil del Docente Tutor/a.

- Plan Tutorial de Aula de acuerdo al Diagnóstico y a los intereses y necesidades de los estudiantes.

- Relación de estudiantes grupo- clase.

- Sesiones de Tutoría.

- Cartel de Normas de Convivencia elaboradas en el aula con los estudiantes.

- Registro anecdotario. e incidencias.

- Cuaderno de incidencias.

- Ficha Personal del estudiante.

\section{Metodología}

La metodología está diseñada para poder ser adaptada y aplicada según las necesidades de las y los estudiantes, así como el manejo de estrategias preventivas promocionales que deberá desarrollar cada tutor/a de aula.

Las estrategias para trabajar la tutoría a nivel de institución educativa son las siguientes:

- La escucha activa.

- Socio drama.

- Dinámicas grupales de animación, reflexivas

- Análisis y reflexión de casos

- Expresión mediante el arte (la música, teatro y danza).

\section{Actividades}

Actividades que se difundirán para la adecuada convivencia y disciplina estudiantil, asimismo para el logro de los objetivos trazados.

TEATRO VIVO: CAMPAÑA PROMOVIENDO EL AUTO IDENTIFICACIÓN Y RECONOCIMIENTO EN MI ESCUELA

"Aprendiendo a reconocer"

- PRIMARIA.

. Pasacalle Interno denominado "Aprendiendo a conocernos" (mimos)

. Video-Fórum en función al reconocimiento de la diversidad cultural. 
. Elaboración de teatro en función a la temática seleccionada.

. Elaboración de recuerdos para la toda la plana docente y administrativa

. Realización de sesiones de tutoría a cargo de cada docente de aula.

\section{DANZA: CAMPAÑA SOMOS DISTINTOS CON LOS MISMO DERECHOS}

"todos somos únicos"

- PRIMARIA.

. Pasacalle Institucional según las diversas regiones "Yo apoyo la diversidad"

.Video Fórum en función a los Derechos del niño centrados en la diversidad cultural.

. Entrega de recuerdos a los que participaron en la danza y promovieron la diversidad cultural.

\section{ENCUENTROS VIVENCIALES: CAMPAÑA CONOCIENDO LAS DIVERSIDADES CULTURALES} "conociendo la diversidad en práctica"

- PRIMARIA.

. Taller vivencial por aula a cargo de El Centro Comunal San Cosme "Aprendiendo artesanía andina"

. Video Fórum en función a los significados de la artesanía (símbolos culturales).

. Diálogo de encuentros vivenciales (experiencias de los participantes)

\section{Presupuesto}

El presupuesto será financiado con recursos de la Institución Educativa, con un fondo fijo de caja chica de 2.500 soles anuales los cuales se irán reponiendo según los gastos; dicho monto es de la partida presupuestal 001-2019 UF-MINEDU-UGEL y peculios de los que ejecutan el presente plan.

\section{Cuadro 3}

Cronograma

\begin{tabular}{|c|c|c|c|c|c|c|c|c|c|c|c|c|c|c|c|c|c|c|c|c|c|c|c|c|}
\hline \multirow{3}{*}{$\mathbf{N}^{\circ}$} & \multirow{3}{*}{ Actividades } & \multicolumn{23}{|c|}{ Tiempo } \\
\hline & & \multicolumn{3}{|c|}{ Mayo } & \multicolumn{4}{|c|}{ Junio } & \multicolumn{4}{|c|}{ Julio } & \multicolumn{4}{|c|}{ Agosto } & \multicolumn{4}{|c|}{ Setiembre } & \multicolumn{4}{|c|}{ Octubre } \\
\hline & & \begin{tabular}{l|l}
1 & 2
\end{tabular} & 3 & 4 & 1 & 2 & 3 & 4 & 1 & 2 & 3 & 4 & 1 & 2 & 3 & 4 & 1 & 2 & 3 & 4 & & & 3 & 4 \\
\hline 1 & Teatro & & & & & & & & & & & & & & & & & & & & & & & \\
\hline 2 & Danza & & & & & & & & & & & & & & & & & & & & & & & \\
\hline 3 & $\begin{array}{l}\text { Encuentros } \\
\text { vivenciales }\end{array}$ & & & & & & & & & & & & & & & & & & & & & & & \\
\hline
\end{tabular}

Fuente de elaboración: propia

\section{CONCLUSIONES}

Las prácticas artísticas revelan la relación que hay entre la cultura producida por un sujeto que es parte de una comunidad y es transformada por ella a la vez (Schwerter, 2014), por lo que es un elemento integrante de la vida cultural y social (Revilla y Olivares, 2019). Por ello es indispensable recalcar que el uso del arte en el aprendizaje fortalecerá la identidad, donde no solo los estudiantes tendrán una valoración de la propia y otras culturas 
(Dalfsen y Corcuera, 2008), sino que la reconocerán y revalorizarán dentro y fuera de su ámbito educativo.

En los lugares donde viven la mayoría de los estudiantes de la muestra se encontró que sí existen actividades artísticas que podrían ser considerados para la educación intercultural en el colegio emblemático del presente estudio. Ante ello es que la propuesta del proyecto toma como insumos para sus actividades justamente esas expresiones artísticas con el objetivo de conectar la educación escolar con el contexto en que vive la mayoría del alumnado; esta es la razón por la que se ha decidido por el teatro, la danza y los encuentros vivenciales en el proyecto.

Se confirmó que los docentes no realizan prácticas relacionadas a la enseñanza de la educación intercultural en sus cursos, lo que representa la principal razón por la que los estudiantes desconocen sobre la interculturalidad. Este desconocimiento también se puede visualizar a través de los comportamientos irrespetuosos entre los compañeros. Ante ello, el colegio debería implementar cursos de capacitación a los profesores para que introduzcan el arte y la interculturalidad en el dictado de sus clases. 


\section{REFERENCIAS BIBLIOGRÁFICAS}

Aguirre, Á. (1997). Cultura e identidad cultural. Introducción a la Antropología. Barcelona: Bardenas.

Alavez, A. (2014). Interculturalidad: concepto, alcances y derechos. México: Cámara de Diputados, Mesa Directiva.

Alvarez, A. (1965). Psicología genética y diferencial. Madrid: Aguilar.

Arias, A., Morales , J., Nouvilas, E., \& Martinez, J. (2012). Psicología social aplicada. Madrid: Panamericana.

Blasco, J., \& Pérez, J. (2007). Metodologías de investigación en las ciencias de la actividad física y el deporte: ampliando horizontes. Alicante: Editorial Club Universitario.

Cabedo-Mas, A., \& Arriaga-Sanz, C. (2016). ¿Música para aprender, música para integrar? Arte y educación en valores en el currículo escolar. DEDiCA. REVISTA DE EDUCAÇÃO E HUMANIDADES(9), 145-160.

Campana, Y., Velasco, D., Aguirre, J., \& Guerrero, E. (2014). Inversión en infraestructura educativa: una a proximación a la medición de sus impactos a partir de la experiencia de los Colegios Emblemáticos. Proyecto Mediano Código: A2-PMN-PM-T10-07-2013. Lima: CIES.

Consejo de Europa . (2008). Libro blanco sobre el diálogo intercultural, vivir juntos con igual dignidad. España: Ministerio de Cultura de España.

Dalfsen, M. V., \& Corcuera, R. (2008). El arte con enfoque intercultural en la escuela. Revista ArtePerú, 46-49.

Estévez, M., \& Rojas, A. (2017). La educación artística en la educación inicial. Un requerimiento de la formación del profesional. Universidad y Sociedad, 9(4), 114-119.

García, C. (2012). ¿Qué puede aportar el arte a la educación? El arte como estrategia para una educación inclusiva. ASRI - Arte y Sociedad. Revista de Investigación $N^{\circ} 1$.

García, V. (1981). Educación Personalizada. Madrid: Ediciones Rialp.

Gonzáles-Mohino, J. C. (2002). Más cerca que lejos: Una propuesta Intercultural a través de la Educación Artística. Arte, Individuo y Sociedad, 14, 49-63.

Hernández, K. V. (2008). Diversidad cultural: Revisión de conceptos y estrategias. cataluña: Departamento de Cultura.

Hernández, M. (2020). Educación intercultural: un déficit en la formación del futuro profesorado [la educación artística como un medio para acabar con la cultura depredadora]. Communiars. Revista de Imagen, Artes y Educacion Crítica y Social(3), 60-75.

Lamus, D. (2012). Raza y etnia, sexo y género: El significado de la diferencia y el poder. Reflexión Política, vol. 14, núm. 27, 68-84. 
León, M., \& Corrales, I. (2016). Influencia intercultural del baile folclórico en las personas adultas mayores del grupo "Alma Joven". Revista Nuevo Humanismo, 4(1), 25-39.

Margulis, M. (2009). Sociología de la cultura: Conceptos y problemas. Buenos Aires: Biblos.

Miranda, K., Zorrilla , J., \& Arellano, J. C. (2013). Autopercepciones de la población afroperuana: identidad y desarrollo. Panamá: Programa de las Naciones Unidas para el Desarrollo.

Mondragón, A. (2010). Interculturalidad, historias, experiencias y utopías. México: Universidad Intercultural del Estado de México / Plaza y Valdés.

Nussbaum, M. (2011). Sin fines de lucro. Por qué la democracia necesita de las humanidades. Madrid: Katz editores.

Ñáñez-Rodríguez, J., \& Castro-Turriago, H. (2016). Educación artística y formación ciudadana: espacio para forjar la sensibilidad en la Corporación Colegio San Bonifacio, de Ibagué, Colombia. Entramado, 12(2), 154-165.

Pizarro, B. (2003). Neurociencia y educación. Madrid: La Muralla.

Revilla, A., \& Olivares, P. (2019). La interculturalidad desde la educación artística. Las posibilidades curriculares a través del arte negroafricano. Revista de educación y humanidades $N^{\circ} 15,173-184$.

Revilla, A., Llevot, N., Molet, C., Astudillo, M., \& Mauri, J. (2015). El diálogo intercultural a través de una mirada al arte africano: una propuesta educativa interdisciplinar. Ehquidad International Welfare Policies and Social Work Journal(4), 71-88.

Rey, G. (2007). Cultura, desarrollo y cooperación. Los reordenamientos de la agenda cultural. Quórum. Revista de pensamiento iberoamericano, núm. 17, 39-48.

Rizo, M. (2005). Me comunico, luego existo El papel de la comunicación en la construcción de identidades. Culturales Vol. $1 N^{\circ} 1,124-142$.

Román, M. (1999). Guía práctica para el diseño de proyectos sociales. Santiago de Chile: CIDE.

Ronchera, M., \& Sales, A. (2020). Conectando miradas. Una autoetnografía del encuentro intercultural artístico. Márgenes, Revista de Educación de la Universidad de Málaga, $1(2), 70-89$.

Ruiz, C. (2003). Educación intercultural. Una visión crítica de la cultura. Barcelona: Octaedro.

Schwerter, L. (2014). Interculturalidad en la educación artística. Congreso Iberoamericano de Ciencia, Tecnología, Innovación y Educación (págs. 1-15). Salvador de Bahía: Organización de Estados Iberoamericanos.

Sirera, B. (2016). El aprendizaje musical y artístico desde una perspectiva intercultural: caso de estudio la Escolanía del Sagrado Corazón de Rosales. DEDiCA. REVISTA DE EDUCAÇÃO E HUMANIDADES, 9, 131-144.

Velarde, P. (2013). El taller arteterapéutico de Teatro Vivo como recurso comunicacional de prevención de la explotación sexual de adolescentes. Canalé, (5), 17-27. 
Revista Enfoques Educacionales - Año 2021 - Vol. 18 No.1: 63-85

Yin, R. K. (1994). Case Study Research, Design and Methods. Applied Social Research Methods. Newbury Park, California: Sage.

Zizek, s. (2011). En defensa de las causas perdidas. Madrid: Ediciones Akal. 